\title{
High school mathematics teachers' competence on the contents of a quantitative research paper
}

\author{
Lany D. Dullas ${ }^{1}$, Samuel R. Soliven ${ }^{2}$ \\ ${ }^{1}$ College of Arts and Sciences, Nueva Vizcaya State University, Bayombong, Nueva Vizcaya, Philippines \\ ${ }^{2}$ Bureau of Curriculum and Development, Department of Education, Philippines
}

\begin{abstract}
Article Info
Article history:

Received Jan 16, 2021

Revised Aug 5, 2021

Accepted Sep 9, 2021

Keywords:

Knowledge competence Novice

Quantitative research writing

Research skill

ABSTRACT

Competence in research is an attractive feature that should be established for all practitioners because specialists with training and expertise in research will recognize strategic thinking, interpretation, and synthesizing more easily. Hence, this study aimed to describe the knowledge competency among junior high school mathematics teachers on the research processes applied on the contents of the various sections of a quantitative research paper. The descriptive method of research has been used to characterize the knowledge competence of 108 junior high school teachers on the research processes. The study used the research skill test, which was a researchermade instrument, consisting of 50 multiple choice items with four choices each. The instrument went through the process of validity and reliability analysis obtaining a good result of 0.81 . This study revealed that they were "novice" or had achieved the learning level of competency on the research processes applied on the contents of the different parts of a quantitative research paper. More so, they identified that interpretation of statistical results was a challenging part of doing a research paper.
\end{abstract}

This is an open access article under the CC BY-SA license.

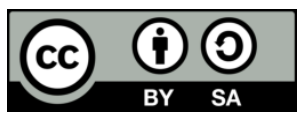

\section{Corresponding Author:}

Lany D. Dullas

College of Arts and Sciences

Nueva Vizcaya State University

Bayombong, Nueva Vizcaya, Philippines

Email: lanydullas@yahoo.com

\section{INTRODUCTION}

The 21 st century is characterized by tremendous outcomes of scientific researches which brought advances in science and technological innovations including the education sector. The realization of global progress has been participated in by UNESCO [1] which supports sustainable development through interdisciplinary research and education. In addition, UNICEF [2] emphasized the concept of quality education which encompasses knowledge, skills and attitudes necessary to realize national goals and positive participation in the society. These agencies reiterate the teacher's role in ensuring quality education through professional knowledge base as explained by Gomendio [3] that teachers should have advanced or graduatelevel education and specialized knowledge of subject matter, pedagogy and classroom management that can be acquired through participation to continuous in-service professional development. Hence, teachers must be equipped with knowledge and skills and a high level of competence in the field of research to respond to the needs of an educational system. Indeed, previous studies [4], [5] emphasized that there is a pressing need for effective education to help develop skills in basic research and publication which contribute positive perspectives and views in the school system. 
Research competency is a significant characteristic that should be developed for all professionals since professionals with knowledge and skill in research will easily understand the systematic thinking, analysis and synthesis [6]. In addition, Khan, et al. [7] explained that some of the components or research competencies of teachers include the pursuit of truth creativity, high intelligence as well as positive attitudes towards research activities. Indeed, Golding [8] found that English mathematics teachers across the Western world made significant change to their teaching through the development of professional skills and knowledge in response to the needs of 21st-century society. As Manfra [9] explained that action research transforms the structure of contemporary educational reform by integrating inquiry and described teachers as researcher-into-practice where action researchers explore and experience professional learning activities as well as issues of everyday practice which would bring change in teaching.

On the other hand, a study [4] explained that learning by actively involving in the research process would enhance their skills such as formulating appropriate research questions, designing and developing methodologically sound studies, gaining ethics approval, collecting and analyzing data, and sharing results. Previous study [10] described research skills in their study as skills constituting communication skills, information seeking skills, research methodology skills and problem-solving skills. It was found in their survey that the research knowledge and skills of a random sample of postgraduate students in a university have moderate knowledge and competencies to conduct research. Similarly, the case study of Barkhuizen [11] showed that English teachers lacked appropriate methodology and knowledge skills in the conduct of research. In addition, research is associated with the search for the useful information from a tremendous amount of information and authenticity of information obtained [12]-[14]. In terms of information literacy skills [15] revealed that majority of the faculty members of a university in Pakistan encountered deficiency in terms of search strategies. Whereas, $17.3 \%$ common variance between web pedagogical content knowledge and online information searching strategies among students of state university in Turkey [16].

In the Philippines, Abarro and Mariño [17] showed that the public secondary and elementary school teachers in the Division of Antipolo City were mildly capable in writing a research proposal and publishable research paper or article. In like manner, Haile [18] found that among secondary school teachers, their practices in conducting action research were very low and involvement was insufficient. Mathematics and science teachers in public schools perceived moderate level of difficulty in conducting action research which implies the need for professional development program in data analysis [19]. Even master teachers in a Philippine educational institution attained a low capability in doing research such as the research processes, research utilization, and research dissemination, attendance to training, attitudes towards research [20]. However, Basilio and Bueno [21] found that master teachers in one of the divisions of Department of Education had fair skills in designing experimental research, developing research instruments, selecting the most appropriate statistical tools. Some of the challenges of doing research as shown from Ulla, Barrera, and Acompanado [22] were lack of knowledge and skills in research, heavy teaching loads and lack of financial support from the schools. Further, writing is not only an important academic skill but a skill that is needed to other career fields [23].

In terms of professional development, the common dilemma is on research requirements of graduate school classes which hinder students to pursue their thesis and dissertation requirements [24], doctoral students of a university encountered challenges and tensions in their research journey. Moreover, Syahrudin [25] surveyed among members of public secondary schools emphasized that professional development is found to be an important strategy to improve the quality of teaching and learning.

The Department of Education [26], [27] reiterates the adoption of the Basic Research Agenda and Basic Education Research Fund which promote the culture of research among basic education teachers. However, Pasion [28] revealed that only $31 \%$ of the public secondary school teachers in the Division, finished Master's and Doctorate degrees, the rest having finished baccalaureate degrees. This finding was consistent with the observation among institutions offering graduate school, that most graduate students in graduate studies, and majority of them are high school teachers, just aimed to finish their academic units and do not continue to finish their thesis writing.

It is on these situations that this study had been conceptualized with greater emphasis among high school mathematics teachers who are mostly graduate school students who possibly had common problems in conducting research requirements in pursuing graduate studies. Thus, this study scrutinized the level of knowledge competence of high school mathematics teachers on the research processes applied on the contents of the different parts of a quantitative research paper namely: title of the study, introduction, related literature, methodology, results and discussion, summary, conclusions and recommendations, and references. 


\section{RESEARCH METHOD}

The descriptive method of research was used to describe the level of knowledge competence of junior high school mathematics teachers on the research processes applied on the contents of the different parts of a quantitative research paper specifically in crafting the title of the study, developing the introduction; organizing the related literature, as well as the methodology, in discussing the results, making the summary, conclusions and recommendations, and citing the references.

In this study, 108 junior high school mathematics teachers from 44 public high schools of the Department of Education located at the Northern and Southern Districts of Nueva Vizcaya responded and participated in the conduct of this study. Academically, $104(96.29 \%)$ of the teachers were graduates of Bachelor of Science in Education or Bachelor in Secondary Education major in Mathematics while three (2.9\%) of them were Bachelor of Science in Mathematics graduates and one of them was a graduate of Bachelor of Science in Information Technology. There were 77 (71.3\%) had units in Master's course, 14 $(13 \%)$ of them finished Master's degree. Among the 14 teachers who had finished their Master's degree, six $(5.6 \%)$ had Doctoral units.

The research skills test was a researcher-made instrument consisting of 50 multiple choice items with four options covering the contents of a research paper. The items of the test illustrated cases and situations and important concepts reflecting the necessary skills of a researcher to be applied in the different processes of developing the parts of a quantitative research paper. Some of the items were based on books in research, internet sources, thesis and dissertations.

The study consisted of three stages. The first stage dealt with the development of the research skill test and the establishments of its validity and reliability with a good result of 0.81 . The second stage was the administration of the research instrument and it was done and given to junior high school mathematics teachers who participated during the five-day seminar conducted by the Department of Education, Division of Nueva Vizcaya on May 2-6, 2017, in which the first day of the seminar was used for the conduct of the study. Finally, Focus Group Discussion (FGD) was also employed after the test.

Data were analyzed using frequency, percent, mean percent scores (MPS) and standard deviations. The mean percent scores were used to describe the level of knowledge competence of the respondents on the research processes applied on the contents of the different parts of a quantitative research paper and were described as novice or learning level, developing proficiency, approaching proficiency, proficiency or mastery and advanced or above proficiency. The descriptions of the levels of competence on research processes applied on the contents of the different parts of a quantitative research paper was adapted from The Department of Education [29].

\section{RESULTS AND DISCUSSION}

\subsection{Knowledge competence of mathematics teachers in crafting a research title}

Table 1 presents the frequency and percent distribution of junior high school mathematics teachers in terms of their obtained scores in the given test item of crafting the title of a quantitative research paper. The result emphasized that the teachers had very low competency in crafting the title of a study. It indicated that teachers were confused of formulating a research title based from the given objectives. Even though they were given a set of specific questions as their basis in formulating the title of the study, they showed difficulty of expressing the research questions into a more creative and general way. The same result was reflected in previous studies [30], [31] which states that the first and foremost difficult task in a research study was identifying the topic for investigation, or area of interest. The result is a reflection of Khankeh, et al. [32] that one of the initial challenges that researchers encounter in the early stages of any research project consisted of identifying the problem as well as forming the questions.

The item given in Figure 1 illustrates the difficulty of teachers in choosing the appropriate research title based on the given research questions. Figure 1 relates that about $51 \%$ of the junior high school mathematics teachers had chosen option B which was not the best possible answer since they were misled for the specific thought of the statement which is all about relationship of the given variables which should have been appropriately written as one of the possible specific questions in the statement of a problem. Teachers were not able to identify the most striking possible answer which mean that the respondents were not much creative in crafting a research title.

Table 1. Frequency and percent distribution of junior high school mathematics teachers (1 item)

\begin{tabular}{ccc}
\hline Scores & Frequency & $\%$ \\
\hline 0 & 88 & 81.5 \\
1 & 20 & 18.5 \\
Total & 108 & 100 \\
\hline
\end{tabular}

Int J Eval \& Res Educ, Vol. 10, No. 4, December 2021: 1202 - 1212 
Item 1 What could be the most appropriate research title of a study with the following given specific problems:

1. What is the level of delinquency of teacher education freshmen students in Mathematics in terms of: a) Physiological factors; $b$ ) attributions from failure; c) Attitudinal encounter; d) Disruptions of peers or technology?

2. What is the level of performance of students in basic mathematics?

3. Are the factors of delinquency significantly related to the performance of the students in basic mathematics?

A. Delinquency in mathematics and performance in basic mathematics of freshmen students (10.2\%)

B. Relationship of delinquency in mathematics and performance in basic mathematics of freshmen students in teacher education (50.9\%)

C. Teachers education freshmen's mathematical delinquency and their performance in basic mathematics (18.5\%)

D. Teachers' education freshmen's mathematical delinquency as influenced by their performance in basic mathematics (20.4\%)

Figure 1. Item in crafting the research title

\subsection{Knowledge competence of mathematics teachers in organizing chapter 1 of a research paper}

Table 2 manifests the level of knowledge competence of junior high school mathematics teachers in organizing the introduction part of a quantitative research paper. Finding can be explained by the research profile of the teachers wherein few of the teachers had conducted thesis in their Master's degree. Their learning level of competence is attributed to their difficulty in writing which includes weak in grammar structure and appropriate and accurate organization of paragraphs and punctuation marks, insufficient ideas and vocabularies as previous studies explained [33]-[35]. It indicated that they lack strategy in relating ideas taken from different sources and they showed insufficient knowledge in organizing the different parts of Introduction of a quantitative research paper.

Figure 2 is one of the items in the research skills test about stating the null hypothesis of a research problem and it also illustrates that the teachers manifested common answers. Test item in Figure 2 which focused on converting specific question to null hypothesis was an easier item among junior high school mathematics since the greatest portion of them (88\%) got the answer correctly. It can be noted that most of the teachers were confident that the null hypothesis was to be written in a negative statement. The item is considered as a very easy item for most of the teachers, but $12 \%$ of them manifested that the item was not familiar to them.

Figure 3 illustrates an item in organizing the "introduction" of a research paper in the research skills test where the teachers manifested varied answers. Whereas, another item in organizing chapter 1 of a research paper (Figure 3) reveals that the different types of definition were unusual among the teachers since only about $28 \%$ of them got the correct answer. The greatest number of the teachers answered option $\mathrm{C}$, since they might have been misled by the described computation but in research, computational definition is not the appropriate term. Similarly, at most $27 \%$ of them answered option A since they might have been misled as well with the first definition but not the definition referred to as emphasized in the study. The least portion of the teachers $(12 \%)$ considered as theoretical definition.

Table 2. Competency level of junior high school mathematics teachers in organizing introduction

\begin{tabular}{ccc}
\hline Scores & Frequency & $\%$ \\
\hline 0 & 2 & 1.9 \\
1 & 2 & 1.9 \\
2 & 7 & 6.5 \\
3 & 20 & 18.5 \\
4 & 27 & 25.0 \\
5 & 28 & 25.9 \\
6 & 18 & 16.7 \\
7 & 3 & 2.8 \\
8 & 1 & 0.9 \\
Mean & \multicolumn{2}{c}{4.27} \\
Sd & \multicolumn{2}{c}{1.28} \\
MPS & 47.42 \\
Level & Novice/Learning level \\
\hline \multicolumn{3}{c}{}
\end{tabular}

Item 1. Which of the following is the null hypothesis of the research problem "Is there a significant difference between the effectiveness of deductive method and inductive method in teaching mathematics?"

What are the significant differences between deductive method and inductive method in teaching mathematics? (2.8\%)

A. There is a significant difference between an effectiveness of deductive method and inductive method in teaching mathematics. (2.8\%)

B. There is no significant difference between the deductive method and inductive method in teaching mathematics. (88\%)

C. Is there a significant difference between deductive method and inductive method in teaching mathematics? (6.5\%)

Figure 2. Item 1 in organizing chapter 1 of a research paper 
Item 2. The term, Academic achievement refers to the knowledge attained and skills developed in a school subject, usually defined by test scores or marks assigned by teachers (Good, 1973). In a study, it consists of the grade point average which was obtained by multiplying the final grade obtained in each academic subject by the number of units and dividing the total by the sum of all the units. The definition is an example of

A. Conceptual definition (26.9\%)

B. Theoretical definition $(12.0 \%)$

C. Computational definition $(33.33 \%)$

D. Operational definition $(27.8 \%)$

Figure 3. Item 2 in organizing chapter 1 of a research

\subsection{Knowledge competence of mathematics teachers in organizing related literature}

Table 3 shows the level of knowledge competence of junior high school mathematics teachers in organizing the related literature part of a quantitative research paper. Results indicated that the teachers had difficulty towards developing a more informative and impressive research because they still need help in accessing and evaluating important contents of information. Obtained from Currie, et al. [36], students did not use as many of the criteria necessary for evaluating sources for a research paper which resulted to obtain relatively few scholarly sources. They confessed in the focus group discussion about their difficulty of connecting ideas generated from different sources to organize related literature and they also admitted that their problem of finding studies related to the topic. The process of translating the contents from reading to writing or the process of paraphrasing is one of the most challenging activity in the field of academic literacy including research [37]. Revealed by Rafique [15], majority of the teachers had encountered deficiency in the choice of information sources, selection of relevant sources, and formulation of search strategies. In addition, Huang [38] elucidated that teachers considered English research writing as independent knowledge which is important in all fields while plagiarism was considered as a serious problem.

Figure 4 is one of the items which showed confusion of teachers in the organization of the related literature and studies. Figure 4 shows that about $42 \%$ of the teachers knew the author-year format of citation, since they got the correct answer which was option A. More than half of the teachers illustrated that their knowledge on citation was inadequate. The result was consistent with what was aired during the focus group discussion when they disclosed that they were not familiar with the American Psychological Association (APA) citation format.

Table 3. Competency level of junior high school mathematics teachers in organizing related literature

\begin{tabular}{ccc}
\hline Scores & Frequency & $\%$ \\
\hline 1 & 1 & .9 \\
2 & 5 & 4.6 \\
3 & 14 & 13.0 \\
4 & 25 & 23.1 \\
5 & 26 & 24.1 \\
6 & 23 & 21.3 \\
7 & 7 & 6.5 \\
8 & 7 & 6.5 \\
Mean & \multicolumn{2}{c}{4.87} \\
SD & 1.54 \\
MPS & 54.12 \\
Level & Novice/Learning level \\
\hline \multicolumn{3}{c}{}
\end{tabular}

Item 2 Which of the following citations is properly stated?

A. Santos emphasized that effective teachers are equipped with the $21^{\text {st }}$ century thinking and learning skills. $(41.7 \%$

B. Santos states that effective teachers are equipped with the $21^{\text {st }}$ century thinking and learning skills. (16.7\%)

C. Effective teachers are equipped with the $21^{\text {st }}$ century thinking and learning skills as cited by Santos. (24.1\%)

D. According to Santos effective teachers are equipped with the $21^{\text {st }}$ century thinking and learning skills. $(17.6 \%)$

Figure 4. Item number 2 in organizing related literature

\subsection{Knowledge competence of mathematics teachers in organizing research methodology}

Table 4 shows the level of knowledge competence of junior high school mathematics teachers in organizing the research methodology part of a quantitative research paper. The choice of the most appropriate methodology is very important to the success of a study but as gleaned from Table 4, nobody got 10 correct items. Attaining a learning level of competence indicated that for situations in which they had acquired the skills in research methodology may not be sufficient to justify their cognitive skills in designing the research 
methodology and can be explained from a study that one of the initial challenges that researchers encounter in the early stages of any research project is selecting an appropriate methodology and design [32]. It can be explained by the reality that only one-fourth of the teachers had attended research seminars/trainings within institutional level and $87 \%$ of them have not obtained Master's degree. From the focus group discussion, they confessed that they did not know when to use and apply the Statistical tools. The result can be traced from Abarro and Mariño [17] indicating that attendance to research seminars and highest educational attainment were some of the factors that affected the research capabilities of secondary and elementary teachers and the finding of Bocar [39] pointed that cooperation of the respondents is difficult to establish. More so, graduate school students encountered challenges in crafting research questions [40]. In addition, Cortes [41] suggested that alignment with the competencies per factor is needed.

Figure 5 is an item of the research skills test, which illustrated confusions of teachers in identifying the appropriate statistics to be used to be described in the research methodology of a research paper. One of the important features of quantitative research writing is the identification and description of appropriate statistics to be used, however, the answers of respondents in the test item given in Figure 5 indicated that they did not have adequate knowledge in the application of the analysis of variance as a statistical tool in a study as they showed varied answers. Only $30.6 \%$ of the junior high school mathematics teachers showed the appropriate knowledge and skill on the application of the identified statistical tool. A greater portion of the teachers need to acquire more knowledge and skills in the application of higher statistics. This finding was attributed from their confession in the focus group discussion that some of them are not teaching statistics and admitted that they already forgot the use and application of higher statistics.

Table 4. Competency level of junior high school mathematics teachers in organizing research methodology

\begin{tabular}{ccc}
\multicolumn{3}{c}{ (10 items) } \\
\hline Scores & Frequency & $\%$ \\
\hline 0 & 1 & 0.9 \\
1 & 7 & 6.5 \\
2 & 19 & 17.6 \\
3 & 28 & 25.9 \\
4 & 30 & 27.8 \\
5 & 20 & 18.5 \\
6 & 2 & 1.9 \\
7 & 1 & 0.9 \\
Mean & & 3.41 \\
Sd & \multicolumn{2}{c}{1.30} \\
MPS & \multicolumn{2}{c}{34.07} \\
Level & Novice/Learning level \\
\hline \multicolumn{3}{c}{}
\end{tabular}

Item 1. Which of the following situations would require the use of mean and analysis of variance?

A. The researcher wishes to investigate the mathematics achievement pattern of high school students aged 12 to 17 at a private school in Nueva Vizcaya. (26.9\%)

B. The researcher wishes to conduct a study on the effect of organic and inorganic fertilizer as supplemental feeds on the growth of tilapia cultured in a fish pond. (7.4\%)

$C$. The researcher wishes to conduct a study on the effectiveness of teaching mathematics using traditional and modern methods to grade 7 students. $(35.2 \%)$

$D$. The researcher wishes to conduct a study on the effectiveness of using three methods of teaching of mathematics by three teachers to grade 10 students. $(30.6 \%)$

No answer $(0.9 \%)$

Figure 5. Item in organizing research methodology

\subsection{Competency level of mathematics teachers in organizing the results}

Table 5 reveals the level of knowledge competence of junior high school mathematics teachers in organizing and discussing the result of a quantitative research paper. Finding indicates that the junior high school mathematics teachers attained the learning level of competence on the contents of Chapter 4 of a quantitative research paper. This result indicated that most of the teachers had difficulty demonstrating the skills of analyzing and interpreting data which implies that they need to be exposed to statistical analysis with the used of software This result was supported by the claim of the teachers that they were not sure of having acquired the skills in problem solving based on some statements pertaining to planning and ways of finding solutions to practical issues or problems. This finding may find bearing from previous studies [42], [43] which concluded that one of the hindrances of teachers in conducting action research was their lack of knowledge in statistics and data analysis. Also, Glancy, et al. [44] observed that students struggle in data

High school mathematics teachers' competence on the contents of a quantitative ... (Lany D. Dullas) 
analysis manifesting difficulty in using certain measurement devices as well as interpretation of test of significance. In addition, Susbiyanto, et al. [45] showed that problem-based learning affects the mastery of research statistical concept. Moreover, this finding is parallel to the findings of the explorative study from abroad conducted by Sismono, et al. [46] among junior high school secondary mathematics teachers which revealed that the difficulty of teachers in problem solving lay in determining the precise mathematical model which in turn explains why teachers had difficulty in identifying the appropriate statistical tool to be applied in data analysis.

Table 5. Competency level of junior high school mathematics teachers in organizing the results

\begin{tabular}{ccc}
\hline Scores & Frequency & $\%$ \\
\hline 1 & 5 & 4.6 \\
2 & 6 & 5.6 \\
3 & 23 & 21.3 \\
4 & 19 & 17.6 \\
5 & 24 & 22.2 \\
6 & 13 & 12.0 \\
7 & 13 & 12.0 \\
8 & 5 & 4.6 \\
Mean & \multicolumn{2}{c}{4.55} \\
Sd & \multicolumn{2}{c}{1.76} \\
MPS & \multicolumn{2}{c}{45.46} \\
Level & Novice/Learning level \\
\hline \multicolumn{3}{c}{}
\end{tabular}

Figure 6 is a one of the items in the research skills test, on which the teachers showed confusion in interpreting statistical results to be discussed in the "results and discussion" of a research a paper. The test item given in Figure 6 was considered a difficult item among the junior high school mathematics teachers since only $7.4 \%$ of them got the correct answer which was option B. More than half of the respondents (57.4\%) answered option A believing that there was no significant difference in the performance of male and female students since they were seemingly misled by the column of mean difference of 4.0070 which was written the same on the rows of equal variances assumed and not assumed. Furthermore, teachers with answers of options C and D did not actually reflect the most important column to be considered in determining significant findings in comparing difference of means which was the Sig. (two-tailed) column. Thus, the result manifests that most of the teachers did not show adequate knowledge and skills in interpreting results generated by statistics software. A similar case was found by Kaleli-Yilmaz [47] in which teachers were not exposed to technology in teaching mathematics. It was then suggested by Li, et al. [48] that technological readiness should be given importance, so that teachers could be able to integrate technology in teaching to be more advance in their teaching endeavors.

\begin{tabular}{|c|c|c|c|c|c|c|c|}
\hline & & $F$ & Sig. & $\mathrm{T}$ & Df & Sig. (2 tailed) & Mean difference \\
\hline \multirow{2}{*}{$\begin{array}{c}\text { Math } \\
\text { achievement } \\
\text { test score }\end{array}$} & $\begin{array}{c}\text { Equal variances } \\
\text { assume }\end{array}$ & 0.537 & 0.466 & 2.697 & 73 & 0.009 & 4.0070 \\
\hline & $\begin{array}{c}\text { Equal variances } \\
\text { not assumed }\end{array}$ & & & 2.724 & 73 & 0.008 & 4.0070 \\
\hline \multicolumn{8}{|c|}{$\begin{array}{l}\text { Which of the following is true between the performance of male and female students? } \\
\text { A. There is no significant difference on the performance of male and female students. }(57.4 \%) \\
\text { B. Male students significantly performed better than female students. }(7.4 \%) \\
\text { C. Female students significantly performed better than male students. }(10.2 \%) \\
\text { D. Sex of students does not affect the performance of students in the achievement test. }(24.1 \%) \\
\text { No answer }(0.9 \%)\end{array}$} \\
\hline
\end{tabular}

Figure 6. Item 1 in organizing the results

Figure 7 shows test item in the research skills test particularly in organizing "results and discussion" of a research paper. It also emphasized that the teachers showed confusion on their answers. On the other hand, the given Statistics software output of the test item given in Figure 7 is an illustration of multiple regression analysis. Majority of the teachers (44.4\%) answered option $\mathrm{C}$ which was not the best answer but they believed that grades in high school and sex of students were independent. On the other hand, teachers who chose option B seemed to have incorrectly interpreted that the higher values of the sig. values of 0.514 
and 0.82 for fathers' education and mothers' education would mean the best predictors of math achievement. Most of the teachers manifested that they did not show adequate knowledge about dependent and independent variables and data analysis in general. It implies that the teachers should be capacitated in terms of their knowledge and skills in interpreting statistical results generated by statistics software.

\begin{tabular}{|c|c|c|c|c|c|}
\hline & $\mathrm{B}$ & Std Error & Beta & $\mathrm{T}$ & Sig. \\
\hline Grades in high school & 1.946 & 0.427 & 0.465 & 4.560 & 0.002 \\
\hline Father's education & 0.191 & 0.313 & 0.053 & 0.610 & 0.514 \\
\hline Mother's education & 0.406 & 0.375 & 0.141 & 1.084 & 0.282 \\
\hline
\end{tabular}

Figure 7. Item 2 in organizing the results

\subsection{Competency level of mathematics teachers in organizing the summary, conclusion, and recommendations}

Table 6 presents the level of knowledge competence of junior high school mathematics teachers in organizing the summary, conclusions and recommendations of a quantitative research paper. It can be inferred from the result of the study that even though the teachers were perceived to have acquired communication skills, they lacked flexibility in their skill in writing specifically in summarizing and in deriving conclusive statements and recommendations in a given study. It was enumerated that the most revealing communication skills applied by teachers were explaining, questioning, and eliciting but not summarizing [49]. This finding would explain that the teachers perceived themselves to have acquired communication skills through their ways of communicating in the field of teaching which may not be sufficient enough to conclude that they were very good in academic writing.

Table 6. Competency level of junior high school mathematics teachers in organizing the summary, conclusion, and recommendations (10 items)

\begin{tabular}{|c|c|c|}
\hline Scores & Frequency & Percent \\
\hline 1 & 3 & 2.8 \\
\hline 2 & 13 & 12.0 \\
\hline 3 & 26 & 24.1 \\
\hline 4 & 30 & 27.8 \\
\hline 5 & 21 & 19.4 \\
\hline 6 & 11 & 10.2 \\
\hline 7 & 3 & 2.8 \\
\hline 8 & 1 & .9 \\
\hline Mean & \multicolumn{2}{|c|}{3.95} \\
\hline $\mathrm{Sd}$ & \multicolumn{2}{|c|}{1.41} \\
\hline MPS & \multicolumn{2}{|c|}{39.54} \\
\hline Level & \multicolumn{2}{|c|}{ Novice/Learning level } \\
\hline
\end{tabular}

Figure 8 is one of the items in the research skills test, which showed confusion among teachers in organizing the summary, conclusions and recommendations part of a research report. Figure 8 shows that more than $50 \%$ of the teachers did not show flexibility in making conclusive statements since they chose options A, C and D which were not considered the best possible answers. This situation implies that the teachers had lack creativity in making conclusive statements. It implies that they also have a problem in terms of their communication skill which is explained that teachers have difficulties in the process of paraphrasing in order to avoid plagiarism and considered summarizing as a complex process in writing [50]. 


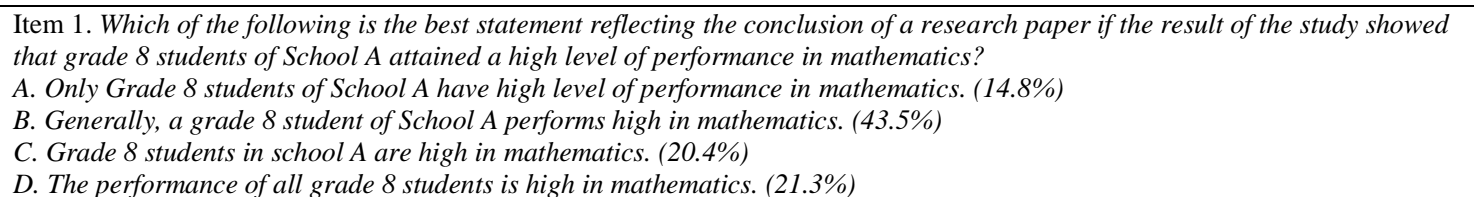

Figure 8. Item 1 in organizing the summary, conclusion, and recommendations

\subsection{Level of knowledge competence of mathematics teachers in writing the references}

Table 7 reveals the frequency and percent distribution of junior high school mathematics teachers in terms of their obtained scores in the given test item of writing the references of a quantitative research paper. Table 7 shows that there was only one item in the research skill test concerning the bibliographic entry of references in APA citation format. The result indicated that they find difficulty writing references to APA format which means that the teachers did not show sufficient knowledge in writing the proper arrangements of the important details of acknowledging the author of a book in APA format. It can be traced from Jomaa and Bidin [51] that doctoral students had insufficient knowledge about using citations and encountered second language difficulties. This finding shows that they are still confused writing the correct arrangement of citations.

Table 7. Frequency and percent distribution of junior high school mathematics teachers (1 item)

\begin{tabular}{ccc}
\hline Scores & Frequency & $\%$ \\
\hline 0 & 55 & 50.9 \\
1 & 53 & 49.1 \\
Total & 108 & 100 \\
\hline
\end{tabular}

\subsection{Overall level of knowledge competence of mathematics teachers on the different parts of a quantitative research paper}

Table 8 shows the summary of the knowledge competence of junior high school mathematics teachers in developing the different parts of a quantitative research paper. The teachers obtained an overall mean percent score of $43.44 \%$ which indicated that they attained a learning level of competence in organizing the content of a quantitative research paper. This result can be attributed to their professional background that is $13 \%$ had finished their Master's course. It implies that the teachers have insufficient knowledge and skills in research writing thus, have difficulty in developing the different parts of a research paper and it is reflected [50] that the performance of junior high school mathematics in their practical test in research writing was "novice". Further, the importance of research is emphasized by previous studies [52], [53] among teacher educators for their professional development.

Table 8. MPS of teachers on the different parts of a quantitative research paper

\begin{tabular}{ccc}
\hline Major parts or process of quantitative research writing & MPS (\%) & Novice/Learning level \\
\hline Crafting a research title & 18.5 & Novice/Learning level \\
Introduction & 47.42 & Novice/Learning level \\
Related literature & 54.12 & Novice/Learning level \\
Methodology & 34.07 & Novice/Learning level \\
Results and discussion & 45.46 & Novice/Learning level \\
Summary, conclusions and recommendations & 39.54 & Novice/Learning level \\
Writing the references & 49.1 & Novice/Learning level \\
Overall & 43.44 & Novice/Learning level \\
\hline
\end{tabular}

\section{CONCLUSION}

Junior high school mathematics teachers manifested a learning level of competence on the processes applied on the content of a quantitative research paper which emphasized that they had a weak academic preparation in research. Hence, a need to participate actively in research seminars, workshops and pursue graduate studies. The Department of Education and corps of research experts from higher educational institutions may collaborate to intensify research training for high school mathematics teachers. Since this study ventured only on the knowledge competence on research process on the content of a quantitative research, a study to gather data about the strengths and weaknesses of the junior high school mathematics teachers on the development of the content of a quantitative research paper and application of research skills. 


\section{REFERENCES}

[1] UNESCO, "Broadening the application of the sustainability science approach," www.unesco.org. [Online]. Available: https://en.unesco.org/sustainability-science/guidelines.

[2] UNICEF, "Defining Quality in Education," A paper presented at the meeting of The International Working Group on Education Florence, Italy, 2000.

[3] M. Gomendio, Empowering and enabling teachers to improve equity and outcomes for all. Paris: OECD Publishing, 2017.

[4] J. Lander, S. Seeho, and K. Foster, "Learning practical research skills using an academic paper framework-An innovative, integrated approach," Health Professions Education, vol. 5, no. 2, pp. 136-145, 2019.

[5] E. Meneses-Paguio, "Toward polishing policies on basic education curriculum change: From the wisdom of the grassroots," The Summit, 2012.

[6] L. Udompong, D. Traiwichitkhun, and S. Wongwanich, "Causal model of research competency via scientific literacy of teacher and student," Procedia-Social and Behavioral Sciences, vol. 116, pp. 1581-1586, 2014.

[7] N. N. Khan, S. Zh. Kolumbayeva, R. K. Karsybayeva, R. A. Nabuova, M. B. Kurmanbekova, and A. Dzh. Syzdykbayeva, "Evaluation of the program effectiveness of research competence development in prospective elementary school teachers," Int. J. Environ. Sci. Educ., vol. 11, no. 18, pp. 12299-12316, 2016.

[8] J. Golding, "Mathematics teachers' capacity for change," Oxford Review of Education, vol. 43, no. 4, pp. 502-517, 2017.

[9] M. Manfra, "Action research and systematic, intentional change in teaching practice," Review of Research in Education, vol. 43, no. 1, pp. 163-196, 2019.

[10] T. S. Mohd Meerah, et al., "Measuring graduate students research skills," Procedia-Social and Behavioral Sciences, vol. 60, pp. 626-629, 2012.

[11] G. Barkhuizen, "Topics, aims, and constraints in English teacher research: A Chinese case study," TESOL Quarterly, vol. 43, no. 1, pp. 113-125, 2009.

[12] M. Attia, and J. Edge, "Be(com)ing a reflexive researcher: a developmental approach to research methodology," Open Review of Educational Research, vol. 4, no. 1, pp. 33-45, 2017.

[13] S. Bhat, N. Kale, M. T. Fernandes, Jas and M. Sanke, "A survey on information retrieval techniques and their performance measures," Int. J. Advanced Res. Comput. Sci., vol. 11, no. 1, pp. 12-16, 2020.

[14] T. Majumder, F. Azam, and A. Rani, "Analysis of fake data on social media," International Journal of Advanced Research in Computer Science, vol. 11, no. 1, pp. 213-217, 2020.

[15] G. M. Rafique, "Information literacy skills of faculty members: A study of the University of Lahore, Pakistan," Library Philosophy and Practice, 2014

[16] G. Tuluk and I. Kepceoglu, "Pre-service teachers' web pedagogical content knowledge and online information searching strategies," International Journal of Evaluation and Research in Education (IJERE), vol. 8, no. 2, pp. 229-236, 2019.

[17] J. O. Abarro and W. P. Mariño, "Research capabilities of public secondary and elementary school teachers in the division of Antipolo City," Int. J. Sci. Res. Pub., vol. 6, no. 6, pp. 407-410, 2016.

[18] B. Haile, "The practice and challenges in conducting action research: The case of Sululta Secondary School," Master Thesis, Addis Ababa University, Ethiopia, 2013.

[19] M. P. E. Morales, E. L. R. Abulon, P. R. Soriano, A. P. David, Ma. V. C. Hermosisima, and M. G. Gerundio, "Examining teachers' conception of and needs on action research," Issues in Educational Research, vol. 26, no. 3, pp. 464-489, 2016.

[20] A. M. Wong, "Driving Forces of Master Teachers' Research Capability: Towards building a research culture in the Division of Romblon, Philippines," International Journal of Advanced Research and Publications, vol. 3, no. 7, pp. 92-97, 2019.

[21] M. B. Basilio and D. C. Bueno, "Research skills and attitudes of master teachers in a division towards capability training," 19th CEBU Philippine International Conference on Economics, Education, Humanities and Social Sciences, 2019, pp. 163-171.

[22] M. B. Ulla, K. I. B. Barrera, and M. M. Acompanado, "Philippine classroom teachers as researchers: teachers' perceptions, motivations, and challenges," Australian Journal of Teacher Education, vol. 42, no. 11, p. 4, 2017.

[23] N. T. Huy, "Problems affecting learning writing skill of grade 11 at Thong Linh high school," Asian Journal of Educational Research, vol. 3, no. 2, pp. 53-69, 2015.

[24] M. Pieridou and M. Kambouri-Danos, "Qualitative doctoral research in educational settings: Reflecting on meaningful encounters," International Journal of Evaluation and Research in Education (IJERE), vol. 9, no. 1, pp. 21-31, 2020.

[25] E. A. Syahrudin, "The role of teachers' professional competence in implementing school based management: study analysis at secondary school in Pare-Pare City of South Sulawesi Province-Indonesia," International Journal of Evaluation and Research in Education (IJERE), vol. 2, no. 3, pp. 143-148, 2013.

[26] Republic of The Philippines, DepEd Order No. 39, 2016. Adoption of the basic education research agenda, Jun. 2016. [Online]. Available: www.deped.gov.ph.

[27] Republic of The Philippines, DepEd Order No. 43, 2015. Guidelines for the Basic Education Research Fund (BERF), Sep. 2015. [Online]. Available: www.deped.gov.ph.

[28] J. Pasion, "Interrelatedness among secondary school teachers' personal and organizational profiles, organizational justice and organizational behavior: groundwork for a revitalization plan," Unpublished Dissertation, Saint Mary's University, Bayombong, Philippines, 2016. 
[29] Republic of The Philippines, DepEd Order No. 73, 2012. Guidelines on the assessment and rating of learning outcomes under the K to 12 basic education curriculum, Sep. 2012. [Online]. Available: www.deped.gov.ph.

[30] P. Balakumar, M. N. Inamdar, and G. Jagadeesh, "The critical steps for successful research: The research proposal and scientific writing: (A report on the pre-conference workshop held in conjunction with the 64th annual conference of the Indian Pharmaceutical Congress-2012)," J. Pharmacol. Pharmacother., vol. 4, no. 2, p. 130, 2013.

[31] R. M. Austria and D. A. Cabonero, "Research knowledge and skills of academic librarians in Northern Philippines," Library Philosophy and Practice, 2020.

[32] H. Khankeh, M. Ranjbar, D. Khorasani-Zavareh, A. Zargham-Boroujeni, and E. Johansson, "Challenges in conducting qualitative research in health: A conceptual paper," Iranian Journal of Nursing and Midwifery Research, vol. 20, no. 6, pp. 635, 2015.

[33] M. Fareed, A. Ashraf, and M. Bilal, "ESL learners' writing skills: Problems, factors and suggestions," Journal of Education and Social Sciences, vol. 4, no. 2, pp. 81-92, 2016.

[34] C. Golding, "Advice for writing a thesis (based on what examiners do)," Open Review of Educational Research, vol. 4, no. 1, pp. 46-60, 2017.

[35] S. Alrabah and S. H. Wu, "Promoting writing competence and positive attitudes among college students in a CLIL English course," International Journal of English Linguistics, vol. 7, no. 1, pp. 58-68, 2017.

[36] L. Currie, F. A. Devlin, J. Emde, and K. Graves, "Undergraduate search strategies and evaluation criteria: searching for credible sources," New Library World, Vol. 111, No. 3/4, pp. 113-124, 2010.

[37] A. Hirvela and Q. Du, ""Why am I paraphrasing?" Undergraduate ESL writers' engagement with source-based academic writing and reading," Journal of English for Academic Purposes, vol. 12, no. 2, pp. 87-98, 2013.

[38] J. C. Huang, "What do subject experts teach about writing research articles? An exploratory study," Journal of English for Academic Purposes, vol. 25, no. 1, pp. 18-29, 2017.

[39] A. C. Bocar, "Difficulties encountered by the student-researchers and the effects on their research output," SSRN, 2009, doi: $10.2139 / \mathrm{ssrn} .1612050$.

[40] B. Daniel, V. Kumar, and N. Omar, "Postgraduate conception of research methodology: implications for learning and teaching," International Journal of Research \& Method in Education, vol. 41, no. 2, pp. 220-236, 2018.

[41] S. T. Cortes, "Needs assessment on action research competencies of teacher-researchers in Surigao del Sur, Philippines," Journal of Education Naresuan University, vol. 21, no. 4, pp. 1-19, 2019.

[42] J. M. Aguilar-de Borja, "Teacher action research: Its difficulties and implications," Humanities \& Social Sciences Reviews, vol. 6, no. 1, pp. 29-35, 2018.

[43] J. M. De Borja, "Teacher action research: Its difficulties and implications," Humanities \& Social Science Reviews, vol. 6, no. 1, pp. 29-35, 2018, doi: 10.18510/hssr.2018.616.

[44] A. W. Glancy, T, J. Moore, S. Guzey, and K. A. Smith "Students' successes and challenges applying data analysis and measurement skills in a fifth- grade integrated STEM unit," Journal of Pre-College Engineering Education Research (J-PEER), vol. 7, no. 1, 2017.

[45] Susbiyanto, D. A. Kurniawan, R. Perdana, and C. Riantoni "Identifying the mastery of research statistical concept by using problem-based learning," International Journal of Evaluation and Research in Education (IJERE), vol. 8, no. 3, pp. 461-469, 2019.

[46] T. Y. E. Sismono, A. W. Kohar, I. Kurniasari, and Y. P. Astuti, "An investigation of secondary teachers' understanding and belief on mathematical problem solving," J. Phys.: Conf. Ser., vol. 693, pp. 1-19, 2015.

[47] G. Kaleli-Yilmaz, "The views of mathematics teachers on the factors affecting the integration of technology in mathematics courses," Australian Journal of Teacher Education, vol. 40, no. 8, pp. 132-148, 2015.

[48] Y. Li, V. Garza, A. Keicher, and V. Popov, "Predicting high school teacher use of technology: Pedagogical beliefs, technological beliefs and attitudes, and teacher training," Technology, Knowledge and Learning, vol. 24, no. 3, pp. 501-518, 2019.

[49] F. M. Yusof and H. Halim, "Understanding teacher communication skills," Procedia-Social and Behavioral Sciences, vol. 155, no. 1, pp. 471-476, 2014.

[50] L. D. Dullas, "Outcomes in Quantitative Research Writing among Junior High School Mathematics Teachers," Journal of Critical Reviews, vol. 7, no. 11, pp. 30-52, 2020.

[51] N. J. Jomaa and S. J. Bidin, "Perspectives of EFL doctoral students on challenges of citations in academic writing," Malaysian Journal of Learning and Instruction, vol. 14, no. 2, pp. 177-209, 2017.

[52] H. A. Alismail and P. McGuire, "21st century standards and curriculum: Current research and practice," Journal of Education and Practice, vol. 6, no. 6, pp. 150-154, 2015.

[53] L. Shi, "Rewriting and paraphrasing source texts in second language writing," Journal of Second Language Writing, vol. 21, no. 2, pp. 134-148, 2012. 